\title{
Enhancing Biomass Energy Efficiency in Rural Households of Ethiopia
}

\author{
Dagninet Amare, Asmamaw Endeblhatu, Awole Muhabaw \\ Bahir Dar Agricultural Mechanization and Food Science Research Centre, Bahir Dar, Ethiopia
}

Email address:

dagnnet@gmail.com (D. Amare), asmaende@yahoo.com (A. Endeblhatu), awolemuhaba@gmai.com (A. Muhabaw)

To cite this article:

Dagninet Amare, Asmamaw Endeblhatu, Awole Muhabaw. Enhancing Biomass Energy Efficiency in Rural Households of Ethiopia. Journal of Energy and Natural Resources. Vol. 4, No. 2, 2015, pp. 27-33. doi: 10.11648/j.jenr.20150402.11

\begin{abstract}
The rural population of Ethiopia entirely depends on biomass for everyday energy needs except for light. The traditional system, particularly during cooking, incurs among others huge energy loss that could have been used otherwise. The system has been recognized as having significant effect on natural resource degradation, harmful health hazards and negative economic consequences. As a result, the government has been encouraging the use of energy saving technologies. Mirt and Gonze stoves are the two most dominantly promoted technologies. Promotion and efficiency evaluations were conducted. The result of the evaluation confirmed that households that use Mirt and Gonze stoves can save more than 33\% and 20\% of wood biomass that could have been used if traditional open stove was used, respectively. The time efficiency, length of time the stoves gave energy to bake additional Injera for Mirt and Gonze was increased by $63 \%$ and 50\%, respectively. Thus, Mirt and stoves are efficient than the traditional open stoves. Due to durability, farmers preferred Mirt stove over Gonze. Utilization of Mirt stove can save 15\% of wood biomass over Gonze. Promotion of Mirt stove in rural Ethiopia is vital to enhance biomass energy efficiency.
\end{abstract}

Keywords: Wood Biomass, Local Stove, Gonze, Mirt, Charcoal, Efficiency

\section{Introduction}

The use of wood as fuel source for heating and cooking is as old as civilization itself. Almost all African countries still rely on wood to meet basic energy need. Wood fuels account for $90-98 \%$ of residential energy consumption in most subSaharan Africa. Ethiopia consumed 0.566 million $\mathrm{m}^{3}$ of wood accounting for $9.1 \%$ of total African cooking and heating wood consumption ${ }^{[1]}$. Fuel wood accounts for around $78 \%$ of the total energy demand in Ethiopia ${ }^{[2]}$.In general, average energy consumption of African households is significant. The average per capita firewood consumption in some African countries for families of 2-6 members was estimated at 1.141.36 tons. Families with seven and greater members consume on average 1.12 tons per capita with the annual to total consumption for an average family of 4.7 persons being 6.4 tons $^{[3]}$.

\subsection{Local Energy Consumption and Sources}

Biomass fuels (firewood, agricultural residues, animal wastes and charcoal) account for up to 90 percent of the energy supply of Ethiopia ${ }^{[1]}$.The households of Zege, on average, had a total annual tree based wood harvest of 3.12 tons per annum where 1.31 tons per annum is extracted for fuel wood by families of 4.2 individuals. The average annual tree based wood consumed was 0.34 tons on adult equivalent and 0.32 tons on per capita bases ${ }^{[4]}$. In Dega and moist Woina Dega agro-ecological zones of Ethiopia, the annual per capita fuel wood consumption is estimated to be $609 \mathrm{~kg}$ and $882 \mathrm{~kg}$ respectively ${ }^{[5]}$.

\subsection{Source of Fuel Wood}

In a study undertaken in Dera woreda, fuel wood was used as source energy for $87.3 \%$ of the households while in combination with animal dung for $12.2 \%$ of the households. Homestead eucalyptus plantation was the major (56.6\%) source ${ }^{[6]}$.Church forests also provide fuel wood for the population while trees in the farm land provide part of the demand. In other studies, approximately $48 \%$ of the households collect fuel wood from common areas ${ }^{[2]}$.

\subsection{Impact of Traditional Energy Utilization System}

Energy utilization in the developing world is a major threat to the environment and health aspects occurring in the rural 
and poor urban households. Lack of clean and affordable energy is recognized as a significant barrier to development and major contributor to a host of environmental and human health problems ${ }^{[1]}$.Reliance on traditional energy sources of biomass brought threat from overuse, creating additional environmental challenges ranging from local land use to global climate change and applications in smoky kitchens ${ }^{[1]}$.If current fuel wood utilization trends continue, most developing countries are predicted to experience severe shortage of fuel wood by 2025 . In sum, it leads to depletion of tree stocks or threat to biodiversity, desertification, reduced water quality, sedimentation, dust storms, air pollution and health problems such as respiratory illnesses and allergies ${ }^{[1][2][5][7]}$.

\subsection{Energy Utilization and Efficiency}

In a scenario of climate change adaptation and biodiversity degradation, reducing the burden on forests is a truthfully critical intervention given the proportion of the population dependent on fuel wood extraction for household energy consumption. At the moment it is impossible to avoid the dependence on wood repay to the lack of alternative energy sources especially electricity. However, increasing the efficiency of the available resource or maximizing the energy available ${ }^{[8]}$ will be a considerable contribution to the agenda of the UN's biodiversity conservation as most are produced from natural forests of indigenous species. It is also important for the country to catch up the rapid development through facilitation of the conservation and management of the natural resource base.

\subsection{Defects of Traditional System}

Given the available traditional energy utilization system, there is extravagancy in energy utilization ${ }^{[8]}$. High biomass energy consumption along with inefficient utilization has contributed for deforestation, biodiversity loss and land degradation $^{[2]}$. In Ethiopia the common and dominant energy system is the open stove system. This system has been described as having several defects. For example much of the energy is lost without purposes owe to its openness and wind condition. Women are exposed for dual health problems. At first the smoke coming from the stove does not have a specific direction, it moves all ways resulting in open exposure of the women for the smoke heat. It is not uncommon to see significant population of the rural women with leaking eyes. Moreover the heat coming from the stove does heart the front leg of the women. It is also common to see darkened and dry front legs of women. The family is also in danger of the health effect as most are done inside or around the house where baby children are also victims of this technology. Thus, the traditional energy production system for baking and cooking is a basic economical and health issue problem at the household level.

\subsection{Strategies Recommended}

Household energy is one of the major problems to the deforestation and subsequent degradation rural areas. Hence, an appropriate energy supply and utilization should be part of the development strategy of a project intervention ${ }^{[1][5]}$.Therefore, large-scale distribution of improved stoves will help to reduce pressure on the biomass resources, eases the conservation of forests, increase land productivity by reducing crop residue and dung usage for fuel wood, and helps to avoid rural health problems arising from smoke and heat during food preparation. The way out is provision of cheap and affordable fuel, afforestation and environmental consciousness through environmental education ${ }^{[1]}$. Further, policies that enhance integrated rural development and promote sustainable energy utilization in rural communities need to be put in place and implemented ${ }^{[9]}$.Increasing efficiency of biomass energy utilization and reduction of wastage in Ethiopia is an important intervention ${ }^{[8][10]}$.Hence, this research activity was designed to evaluate, select and promote the most viable energy saving technology to the rural population of the country.

\section{Objectives}

The objective of this research was to evaluate, select and promote the most efficient energy saving technology to the farmers

\subsection{Materials and Methods}

The demonstration and evaluation was conducted in Enqulal watershed of Dera woreda, Amhara region, North West Ethiopia. Overall 29 female farmers were selected randomly and trained. Out of which 3 female farmers were selected based on accessibility and willingness for evaluation of the stoves.

\subsection{Technology Description}

The Mirt and Gonze molds has totally eight different materials each, it was manufactured from $1.5 \mathrm{~mm}$ sheet metal, round iron, flat iron and square pipe. It has two half circles, the external diameter of the circle has $325 \mathrm{~mm}$ and the internal side of diameter $285 \mathrm{~mm}$ which manufactures the sides of the stoves. The mold also has two materials the wood intern and the smock exit.

Mirt stove: A Mirt stove has groves that the components fit to each other. The average price of the Mirt stove in much of the markets in the region is 100 ETB. The components of Mirt stove energy saving stove mold are side mold, exit smock mold, wood intern mold and mold for dish.

Gonze stove: Gonze is made with mold but with no groves rather each closing another component. Thus the Gonze thou has a maximum diameter, to the size of the mold, does not have a minimum diameter. It can be reduced to suit the purpose or size of the stove.

Local stove: it is an open stove where three medium sized stones are used to put the "Mitad". It is open except the spaces occupied by the stones. 


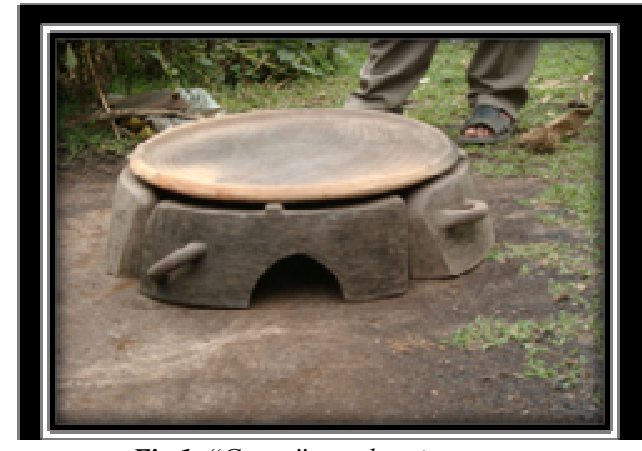

Fig.1. "Gonze" wood saving stove.

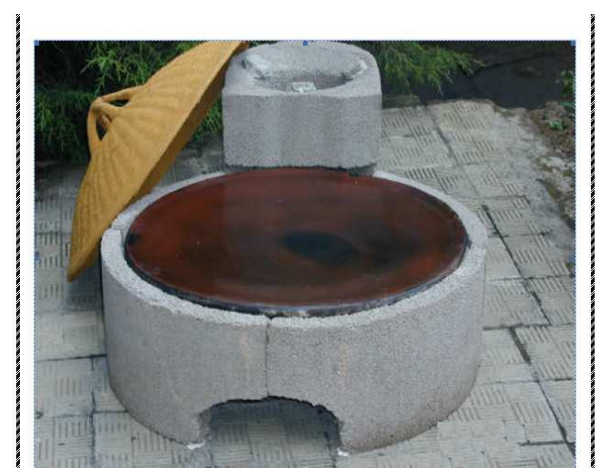

Fig. 2. Mirt" wood saving stove.

\subsection{Methodology of Training and Evaluation}

\subsubsection{Initial Survey}

Assessment on the status of kitchens and the availability of local materials and other improved fuel saving technologies will be carried out.

\subsubsection{Selection of Farmers}

As to the plan a site was selected in Dera woreda. The area selected is Enqulal watershed whereby 29 female farmers from both male and female headed households from 7 kebeles were selected. Women were selected from Enqulal watershed comprising 7 kebeles (29) with the help of the project technicians. The women selected were from both men $(90 \%)$ and women headed households $(10 \%)$.

\subsubsection{The Experimental Women's Kitchens}

The women selected for this evaluation were married and 40 years of age on average. They are experienced bakers of Injera spanning for more than half of their age. They were selected due to their houses accessibility (nearest to the road) and willingness to undertake the evaluation by sacrificing their time. The procedure provided to the evaluation women were installing in their kitchens, preparation of yeast according to the tradition and acquaintance with the new stoves for two weeks.

\subsubsection{Test Condition}

Given the requirements of the test the team decided to take major energy using stages like the first firing and the last heat that still helps to bake. Thus, it was reached that a sample for each of the three stoves on three women for Injera baking, the most energy consuming activity, was considered vital $^{[2][5]}$. Besides, the least energy consuming activities like coffee and stew "wot" preparation were not considered separately. This is due to the priority that much of the energy consumption and health problems occur in Injera baking, which is the sole dominant bread for the Northern Ethiopian population.

\subsection{Data Collection and Analysis}

\subsubsection{Data Collection on Measurements and Time}

During data collection, three replications for each stove model were conducted. Each stove was given a chance of to bake 10 Injera but time was recorded when there is also additional heating value. Consequently, with the acquisition of Mirt and Gonze stove, evaluations were done one after the other in two cases and two parallels in one case. The weight of wood before baking at first for each stove, the size of wood left and amount of charcoal obtained after the time where there was not possible to bake any more Injera was measured using a spring balance of size $50 \mathrm{kgs}$ and the length of time of energy available for baking additional Injera. Farmers feedback was collected both during the training and evaluation sites.

\subsubsection{Data Analysis}

Data was analyzed using simple descriptive statistics on excel 2007 and Stata 11 software.

\section{Result and Discussion}

\subsection{Household Energy Source Condition in the Area}

The area belongs to the highlands of Ethiopia, and from observation it is highly degraded. Thou mixed farming takes place, due to the feed problem, the amount of dung extracted from animals is barely enough. The major energy source in the area is eucalyptus tree. As a result, the women participants expressed the presence of acute shortage of fuel wood for cooking. The energy source for lightening in most households, is gasoline thou there is extensive expansion rural electrification all over the country. Besides, it is optimistic ${ }^{[5]}$ to assume that the rural community will use electricity for cooking activities given the supply of kitchen appliances along with a price level deemed and the knowledge of utilization that is also low in the urban areas.

\subsection{Energy Shortage}

The vast majority of rural people who are also dependent on traditional fuels use primitive and inefficient technologies ${ }^{[1]}$.As a result, $25.4 \%$ of the respondents indicated that energy shortage is a problem in the area. However, only $4 \%$ of the respondents use energy saving technology (fuel stoves made from mud) as a means to compensate for energy shortage. Focus group discussion participants, in Dera woreda, demanded delivery of cement made energy saving stoves. Locally made energy saving stoves, mud, has been used by some households but they break up within days resulting in 
reluctance to use them.

\subsection{Training of the Women Farmers}

\subsubsection{Theoretical}

House hold and husbanded females were trained on the concepts of fuel wood crises and its effect on ecology, by displaying other region or country's experience supporting with pictures photos and movies using laptop and LCD using the training manual prepared.

\subsubsection{Practical Production of the Stoves}

Two models of Mirt and Gonze wood saving stoves were used for training. During the practical training, the team produced six Mirt and four Gonze stoves. Ultimately, the stoves were given to farmers training center for display including one model made of local material. For the purpose of encouragement some 33 "Mitad"s were bought from Addis Zemen and given to them for further works.

\subsubsection{Stove Energy Efficiency Evaluation}

The type of energy used in this locality is biomass energy resources except for lightening at night which is either kerosene or electricity for some households. They are entirely dependent on wood biomass. The energy biomass from dung is insignificant due to herd and feed reduction.The following table shows the evaluation condition at the beginning of the experimentation.

Table 1. Fuel efficiency of the stoves.

\begin{tabular}{|c|c|c|c|c|c|}
\hline Variable & Observation & Mean & Std. Dev. & Min & Max \\
\hline Total fuel wood available at first (kg) & 9 & 8.49 & 0.75 & 7 & 9.2 \\
\hline Amount of fuel wood burnt (kg) & 9 & 3.76 & 1 & 2.4 & 5 \\
\hline Amount of time burnt ( minutes) & 9 & 59.11 & 15.01 & 39 & 80 \\
\hline Size of charcoal obtained after the burn ( $\mathrm{kg}$ ) & 9 & 0.10 & 0.09 & 0 & 0.24 \\
\hline
\end{tabular}

\subsubsection{Amount Wood Consumed}

The following graph shows the performance of the stoves under three sample households (women). The weight of wood burnt by three stoves to bake ten Injera (Ethiopian tradition flat breads) was evaluated at three different kitchen cells of by three women.

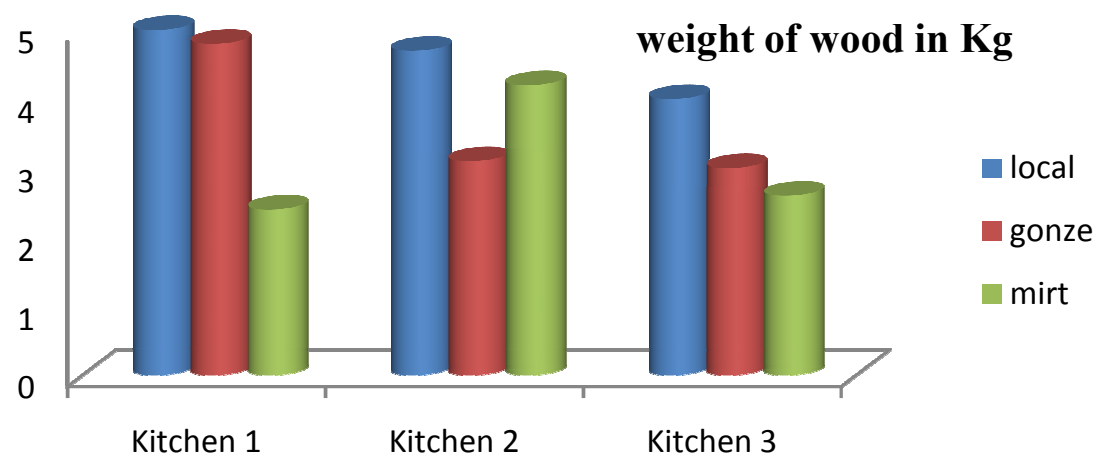

Fig. 3. Weight of wood burnt by the respective stoves in each woman's kitchens.

The weight of wood burned in the first woman's kitchen, the amount of wood burned by Gonze and local stoves looks more of equal while the weight was more than half by Mirt stove. In the second woman's condition the amount of wood burnt using local stove and Mirt was comparably similar while Gonze was the smallest.

Table 2. LSD of wood burnt in $\mathrm{kg}$.

\begin{tabular}{lllllll}
\hline \multirow{2}{*}{ (I) type of stove } & (J) type of stove & Mean Difference (I-J) & Std. Error & Sig. & \multicolumn{2}{c}{$\mathbf{9 5 \% \text { Confidence Interval }}$} \\
& & & & & Lower Bound & Upper Bound \\
\hline \multirow{2}{*}{ Traditional } & Gonze & 0.933 & 0.709 & 0.236 & -0.801 & 2.667 \\
& Mirt & 1.50 & 0.709 & 0.079 & -0.234 & 3.234 \\
\multirow{2}{*}{ Gonze } & Traditional & -0.933 & 0.709 & 0.236 & -2.667 & 0.801 \\
& Mirt & 0.567 & 0.709 & 0.454 & -1.167 & 2.301 \\
\multirow{2}{*}{ Mirt } & Traditional & -1.50000 & .70868 & .079 & -3.2341 & .2341 \\
& Gonze & -.56667 & .70868 & .454 & -2.3007 & 1.1674 \\
\hline
\end{tabular}

In the third woman's kitchen the weight of wood burnt progressively increased from Mirt to Gonze and then local. In 
general, the amount of wood burnt to bake 10 Injera was averagely low for Mirt and the highest for local stove. One way ANOVA showed the absence of statistical difference $(\mathrm{F}=2.28, \mathrm{p}=0.1829)$ on the weight of wood consumed both by the three stoves and the women's kitchens. In general, Mirt and Gonze consumed $67.15 \%$ and $79.56 \%$ of the wood consumed by traditional stove. Mirt burned only $84.40 \%$ of the amount of wood consumed by Gonze stove.

\subsubsection{Length of Time}

The length of time refers to the number of minutes the three stoves under the three experimental women have performed. Gonze stove was providing heat for baking Injera for longer periods in the second woman's kitchen.

More importantly, the length of time Mirt stove provided heat to bake additional Injera after the $10^{\text {th }}$ Injera was baked and the wood is avoided was almost constantly similar. Similarly, the length of time the local stove provided heat to bake additional Injera was comparatively the lowest in all three conditions. This condition does not considered the amount of heat the stove provided parallel to stew making and water boiling in adjacency.

Table 3. ANOVA for burning time.

\begin{tabular}{llllll}
\hline Source & SS & df & MS & F & Prob $>$ F \\
\hline Between groups & 1216.22 & 2 & 608.11 & 6.22 & 0.0345 \\
Within groups & 586.67 & 6 & 97.78 & & \\
Total & 1802.89 & 8 & 225.36 & & \\
\hline
\end{tabular}

Bartlett's testfor equal variances: $\operatorname{chi} 2(2)=2.0244 \mathrm{Prob}>\operatorname{chi} 2=0.363$.

ANOVA showed the presence of significant difference in length of time the wood burned among the three stoves. The length of time the stoves gave energy sufficient to bake additional 'Injera' was 1.63 and 1.5 times the length of traditional stove burned, for Mirt and Gonze respectively. Mirt gave a burning time of 0.08 times longer than Gonze.

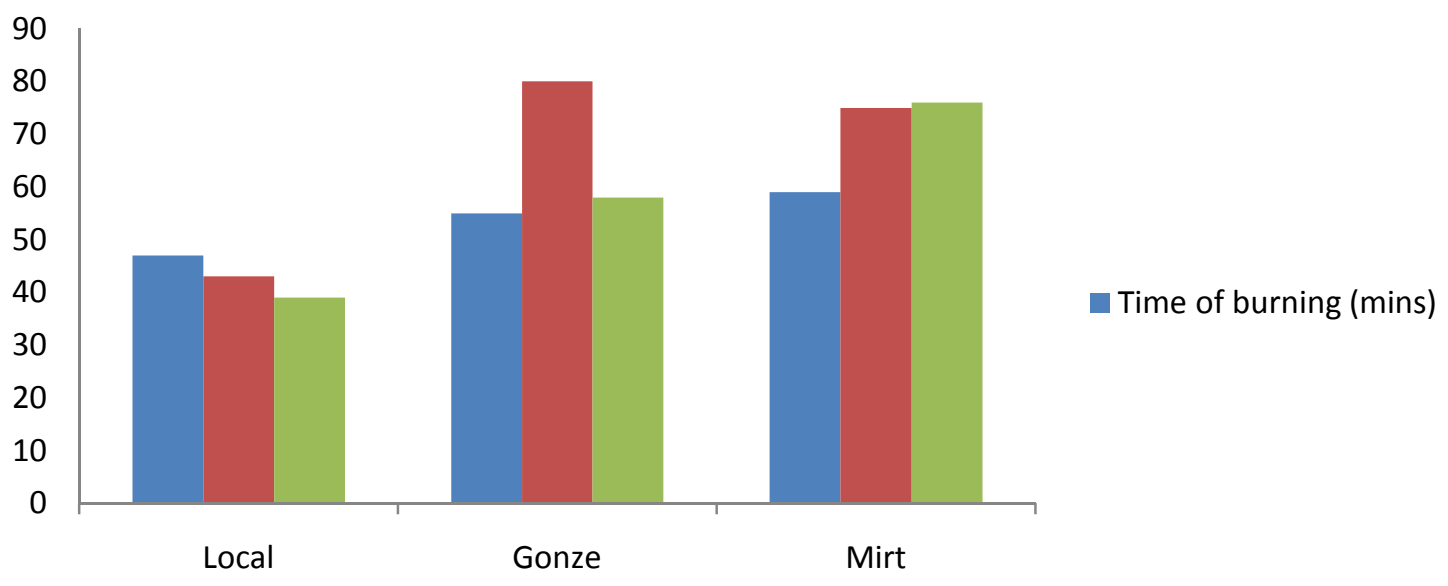

Fig. 4. Length of time of burning after baking of the $10^{\text {th }}$ Injera.

\subsubsection{Amount of Charcoal Extracted}

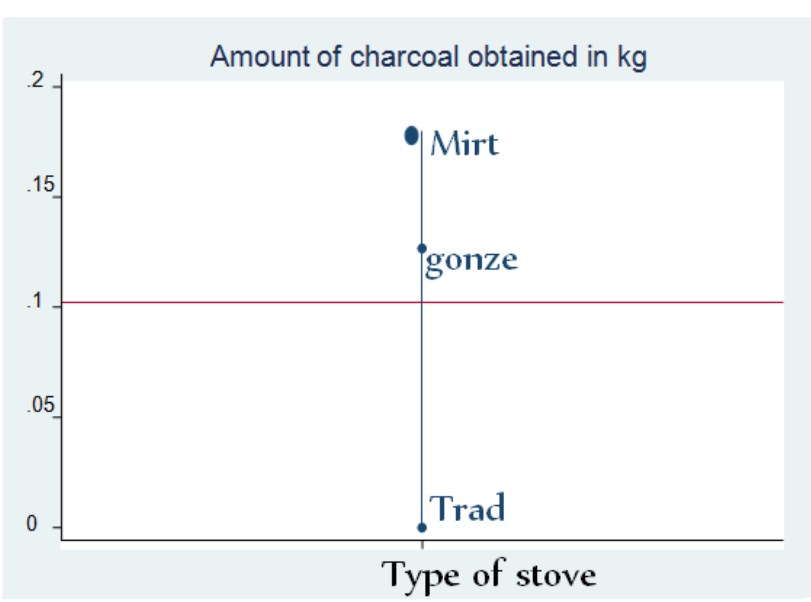

Fig. 5. Amount of charcoal extracted.

The amount of charcoal extracted after termination of the evaluation was measured. The local stove for Injera baking has no charcoal extract. The weight of charcoal extracted from Mirt stove was averagely higher than that of Gonze. The amount of charcoal extracted from burned wood of traditional stove was nil due to the use of small size sticks that are highly blazing. This is due to the inability to continuously flap the heat to burn that the wood should be mostly sliced thinly. This incurs damage to what would have been saved as a by-product (charcoal) to be used for stew and coffee making. Thou, the amount is zero here, it is extracted in most cases however very grainy in observation from experience.

Table 4. ANOVA for charcoal extracted.

\begin{tabular}{llllll}
\hline Source & SS & df & MS & F & Prob $>$ F \\
\hline Between groups & 0.051 & 2 & 0.026 & 7.99 & 0.0204 \\
Within groups & 0.019 & 6 & 0.0032 & & \\
Total & 0.071 & 8 & 0.009 & & \\
\hline
\end{tabular}

Bartlett's test for equal variances: $\operatorname{chi} 2(1)=0.0102$ Prob $>\operatorname{chi} 2=0.920$

One way ANOVA showed the presence of significant difference $(\mathrm{F}=7.99, \mathrm{p}=0.0204)$ in amount of charcoal extracted from the three stoves among the three stoves. 


\subsubsection{Overall Evaluation}

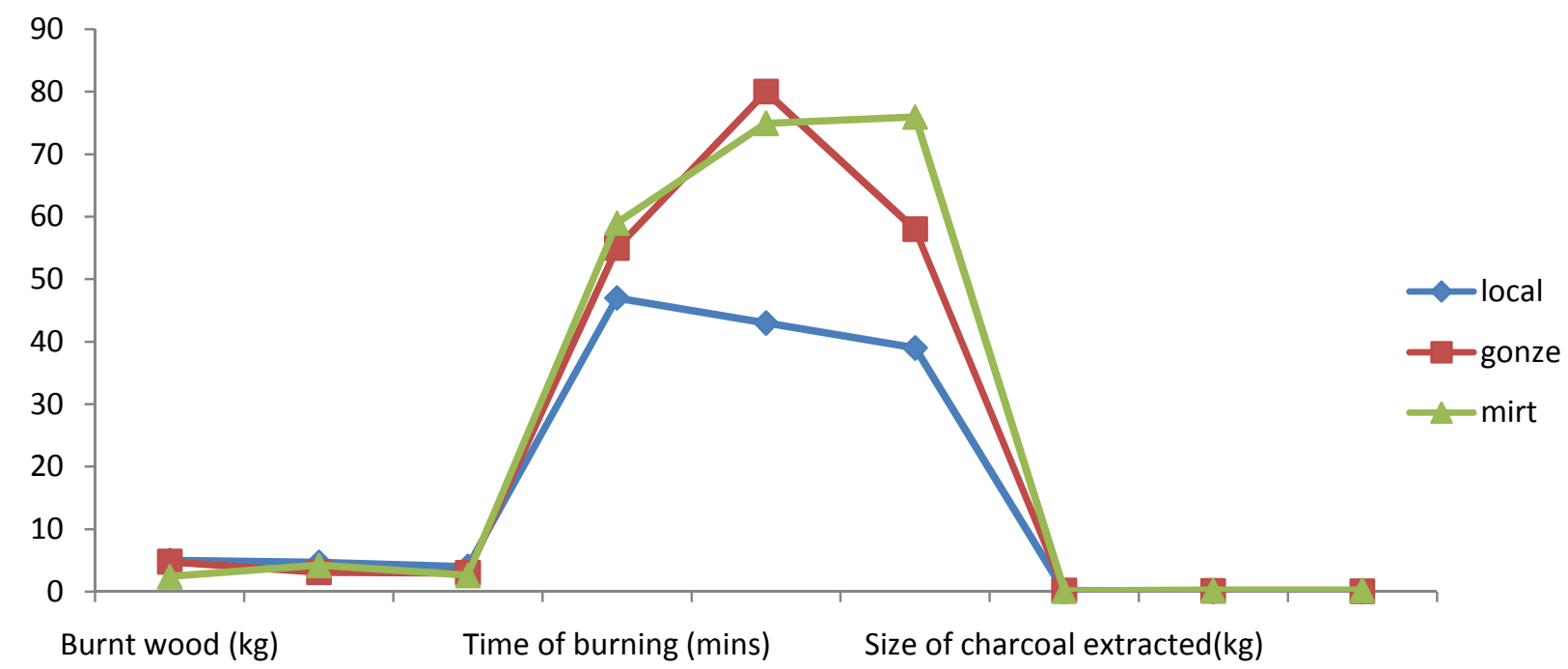

Fig. 6. Overall efficiency.

According to Dagninet et al. $(2012)^{[1]}$, the annual wood consumption for fuel will be 0.22 tons and 0.26 tons per capita bases. On adult equivalent bases the annual wood consumed will be 0.23 tons and 0.27 tons respectively for Mirt and Gonze stoves. On the other hand annual consumption efficiency can be calculated by considering the area as a moist Woina Dega livelihood zone ${ }^{[11]}$. Thus, annual per capita fuel wood consumption will roughly be $596 \mathrm{~kg}$ and $703 \mathrm{~kg}$ for Mirt and Gonze stoves respectively. It helps to save $290 \mathrm{~kg}$ and $180 \mathrm{~kg}$ of fuel wood annually on per capita bases. In general Mirt stove showed a comparatively better performance in terms of burning time and charcoal extracted relative to Gonze and traditional stoves. Gonze has a comparatively energy efficiency and wood reduction advantage compared to local stove. The Mirt stove has a better energy efficiency compared to both traditional and Gonze stoves.

Table 5. LSD of length of time wood burnt in minutes.

\begin{tabular}{|c|c|c|c|c|c|c|}
\hline \multirow{2}{*}{ (I) type of stove } & \multirow{2}{*}{ (J) type of stove } & \multirow{2}{*}{ Mean Difference (I-J) } & \multirow{2}{*}{ Std. Error } & \multirow{2}{*}{ Sig. } & \multicolumn{2}{|c|}{ 95\% Confidence Interval } \\
\hline & & & & & Lower Bound & Upper Bound \\
\hline \multirow{2}{*}{ Traditional } & Gonze & $-21.33^{*}$ & 8.07 & 0.038 & -41.09 & -1.58 \\
\hline & Mirt & $-27.00^{*}$ & 8.07 & 0.016 & -46.76 & -7.24 \\
\hline \multirow{2}{*}{ Gonze } & Traditional & $21.33^{*}$ & 8.07 & 0.038 & 1.58 & 41.09 \\
\hline & Mirt & -5.67 & 8.07 & 0.509 & -25.42 & 14.09 \\
\hline \multirow{2}{*}{ Mirt } & Traditional & $27.00^{*}$ & 8.07 & 0.016 & 7.24 & 46.76 \\
\hline & Gonze & 5.67 & 8.07 & 0.509 & -14.09 & 25.42 \\
\hline
\end{tabular}

*Mean difference is significant at the 0.05 level.

\subsection{Women's Feedback}

The test women reflected during the trial on the benefits and shortages of each stove. They preferred the Mirt stove due to longevity of age and ability to contain the heat for longer periods. Dissatisfaction on Gonze stove rose mainly due to loss of energy and breakability. Compared to the local stove, Mirt requires longer heating period and more solid wood while it is possible with leaves and thin wood slots that Injera is baked in local stove. All of the women preferred Mirt stove due to the benefits of energy saving, avoidance of smokes and front leg burning. Alongside women, male partners showed a heightened interest for the Mirt stove. Overall, they ranked from first to last Mirt, Gonze and traditional according decreasing trend of preference.

\subsection{Opportunities for Promotion}

The most valuable opportunities for promotion and adoption of the technology are the ever increasing shortage of biomass energy resources, the consciousness of the male partners about the health problems faced by their wives, especially their eyes and legs and the willingness to pay the market price of the stove (100-150birr). The policy inclination towards stall feeding is forcing people to own fewer sizes of cattle than used to be. This reduces the amount of dung available for energy. Thus, the importance of energy saving technologies will be crucial that makes promotion easier. However, for this specific area, there was mismatch in diameter of "Mitad" available in the local market and the diameter of the stove. Hence there is a need to modify to the 
required size.

\section{Conclusion}

The stoves increase efficiency of available energy utilization. Mirt and Gonze stoves help to save 33\% and 20\% of the average annual energy consumption per household, respectively. Efficiency could also be improved since there was a slight difference between the "Mitad" and the Mirt stove. Hence, reduction of the diameter of Mirt stove for that particular locality to encourage more adoption is vital. The farmers explained that while Gonze is useful as it does not permanently occupy a space, there is a problem of loss of heat and hence uses more fuel wood. In the case of Mirt stove, they explained that it takes longer time and relatively high amount of wood at the beginning for heating but after heating it helps to bake more than that can be done with local stove while the avoidance of smoke is considered vital.In general, the supply of a mold or Mirt stove design that fits to the diameter of the local "Mitad"s (averagely $56 \mathrm{~cm}$ from a sample of 28 "Mitad"s compared to $62 \mathrm{~cm}$ of the Mirt mold availed) helps to improve rural energy efficiency in Ethiopia.

\section{References}

[1] David. J Idiata, Mitchell Ebiogbe, Henry Oriakhi, and Osazuwa. L Iyalekhue, 2013. Wood Fuel Usage and the Challenges on the Environment. International Journal of Engineering Sciences, 2(4).Pps: 110-114.

[2] Abebe Damte, Steven F. Koch, and Alemu Mekonnen, 2012. Coping with Fuelwood Scarcity: Household Responses in Rural EthiopiaEnvironment for Development, discussion paper series (EfD DP 12-01).
[3] Bembridge, T.J. and J.E. Tarlton, 1990. Wood fuel in Ciskei: A Head load Study. SouthAfrican Forestry Journal, 154: 88-95.

[4] Dagninet Amare, Assefa Seyoum and Fekadu Beyene, 2012. The Remnants Forest Patches of Zege Peninsula, Ethiopia: Livelihood Strategies, Institutional Arrangements and Forest Products Extraction. Lambert Academic Publishing AG \& Co KG.

[5] Susanne Geissler, Dietmar Hagauer, Alexander Horst, Michael Krause, Peter Sutcliffe,2013. Biomass Energy Strategy Ethiopia.23rd December, 2013. Energy for development Pdf.

[6] Beyene Belay and Dagninet Amare, 2014. Integrated Forest Management Plan in Five Selected Church Forests In Dera Woreda: Implication For Ecological Restoration and Biodiversity Conservation. Forest Management Plan Report Submitted to NABU Bahir Dar Office. Bahir Dar, Ethiopia. April 2104, unpublished.

[7] Audu, E.B., 2103. Fuel wood consumption and desertification in Nigeria. International Journal of Science and Technology, 3(1). ISSN 2224-3577

[8] Melis Teka, 2006. Energy Policy of Ethiopia, Ministry of Mines and Energy. Geothermal Energy Conference, Addis Ababa, Ethiopia.24-29 November 2006.

[9] Masekoameng K.E., Simalenga T.E. and Saidi T,2005. Household energy needs and utilization patterns in the Giyani rural communities of Limpopo Province, South Africa Journal of Energy in Southern Africa.16 (3).

[10] Dessie Tarekegn Bantelay, Nigus Gabbiye. Design, Manufacturing and Performance Evaluation of House Hold Gasifier Stove: A Case Study of Ethiopia. American Journal of Energy Engineering. Vol. 2, No. 4, 2014, pp. 96-102. doi: 10.11648/j.ajee.20140204.12. 